BNL-114563-2017-JA

\title{
Dissolution of Pt during Oxygen Reduction Reaction Produces Pt Nanoparticles
}

\author{
J. H. Bae, H. L. Xin \\ Accepted by acs.analchem.
}

October 2017

Center For Functional Nanomaterials

Brookhaven National Laboratory

\author{
U.S. Department of Energy \\ USDOE Office of Science (SC), \\ Basic Energy Sciences (BES) (SC-22)
}

\footnotetext{
Notice: This manuscript has been co-authored by employees of Brookhaven Science Associates, LLC under Contract No. DE-SC0012704 with the U.S. Department of Energy. The publisher by accepting the manuscript for publication acknowledges that the United States Government retains a non-exclusive, paid-up, irrevocable, world-wide license to publish or reproduce the published form of this manuscript, or allow others to do so, for United States Government purposes.
} 


\section{DISCLAIMER}

This report was prepared as an account of work sponsored by an agency of the United States Government. Neither the United States Government nor any agency thereof, nor any of their employees, nor any of their contractors, subcontractors, or their employees, makes any warranty, express or implied, or assumes any legal liability or responsibility for the accuracy, completeness, or any third party's use or the results of such use of any information, apparatus, product, or process disclosed, or represents that its use would not infringe privately owned rights. Reference herein to any specific commercial product, process, or service by trade name, trademark, manufacturer, or otherwise, does not necessarily constitute or imply its endorsement, recommendation, or favoring by the United States Government or any agency thereof or its contractors or subcontractors. The views and opinions of authors expressed herein do not necessarily state or reflect those of the United States Government or any agency thereof. 


\title{
Dissolution of Pt during Oxygen Reduction Reaction Produces Pt
}

\section{Nanoparticles}

\author{
Je Hyun Bae, ${ }^{\dagger, \downarrow}$ Ricardo F. Brocenschi, ${ }^{\dagger, \downarrow}$ Kim Kisslinger, ${ }^{\S}$ Huolin L. Xin,${ }^{\S}$ and \\ Michael V. Mirkin ${ }^{\dagger}, \|, *$
}

$\dagger$ Department of Chemistry and Biochemistry, Queens College - CUNY, Flushing, NY 11367

$\S$ Center for Functional Nanomaterials, Brookhaven National Laboratory, Upton, NY 11973

"The Graduate Center, CUNY, New York, NY 10016

*Corresponding Author

E-mail:mmirkin@qc.cuny.edu

FAX: 718-997-5531 


\begin{abstract}
The loss of Pt during the oxygen reduction reaction (ORR) affects the performance and economic viability of fuel cells and sensors. Our group previously observed the dissolution of $\mathrm{Pt}$ nanoelectrodes at moderately negative potentials during the ORR. Here we report a more detailed study of this process and identify its product. The nanoporous Pt surface formed during the ORR was visualized by AFM and high-resolution SEM, which also showed $\sim 5 \mathrm{~nm}$ sized Pt particles on the glass surface surrounding the electrode. The release of these nanoparticles into the solution was confirmed by monitoring their catalytically amplified collisions with a $\mathrm{Hg}$ coated microelectrode used as the tip in the scanning electrochemical microscope (SECM).
\end{abstract}


Pt is widely used as a catalyst and electrode material in fuel cells, electrochemical sensors, and medical equipment. Dissolution of Pt that can affect the performance and durability of these devices has been observed and studied under anodic ${ }^{1-8}$ and cathodic ${ }^{9-11}$ polarization. The mechanism of this process and the nature of the products depend on the experimental conditions. In several studies Pt dissolved via oxide formation and subsequent reduction at more negative potentials. ${ }^{1-8}$ The dissolution at extreme cathodic potentials (e.g., $E<-5 \mathrm{~V}$ vs. NHE) produced nanoparticles (NP), ${ }^{9}$ while cathodic corrosion in $10 \mathrm{M} \mathrm{NaOH}$ at $E \leq-1.3 \mathrm{~V}$ vs. NHE resulted in highly anisotropic etching. ${ }^{10}$ We reported Pt dissolution at moderate negative potentials during the oxygen reduction reaction (ORR) in water and organic media that was unrelated to oxide formation. ${ }^{12}$ The loss of Pt in ref. 12 observed by imaging of Pt nanoelectrodes with the atomic force microscope (AFM) before and after the ORR appeared to occur under the same conditions as the production of hydroxyl radical $\left(\mathrm{HO}^{\circ}\right) .{ }^{13}$ Percival et al. ${ }^{14}$ suggested that highly oxidizing $\mathrm{OH}^{*}$ is responsible for Pt dissolution during ORR and detected oxidized Pt species in solution. Here our focus is on identifying the product of Pt dissolution that accompanies the ORR. In Fig. 1, two AFM images of the same Pt electrode were obtained before (A) and after (B) applying a sequence of $4001 \mathrm{~s}$ slong anodic $(-0.15 \mathrm{~V} v s$. NHE) and cathodic $(-0.75 \mathrm{~V} v s$. NHE) potential pulses in solution containing $5 \mathrm{mM} \mathrm{KNO}_{3}$ and $20 \mathrm{mM} \mathrm{N}_{2} \mathrm{H}_{4}$ to induce ORR-related $\mathrm{Pt}$ dissolution $^{12,13}$ (for details, see Supporting Information). The anodic pulse potential was slightly more negative than that in ref. 12 to avoid oxidation of hydrazine. ${ }^{15}$ From the cross-section in Fig. 1A, the electrode radius $(a)$ is $\sim 200 \mathrm{~nm}$, and the conductive surface is recessed into glass insulator by $\leq 12 \mathrm{~nm}$. After the ORR (Fig. 1B), the recess depth $(l)$ increased to $\sim 65 \mathrm{~nm}$ due to the loss of Pt. Appropriate protection was used in our experiments to avoid electrostatic damage to the nanoelectrode ${ }^{16}$ that could look similar to the Pt loss occurring during the ORR. 


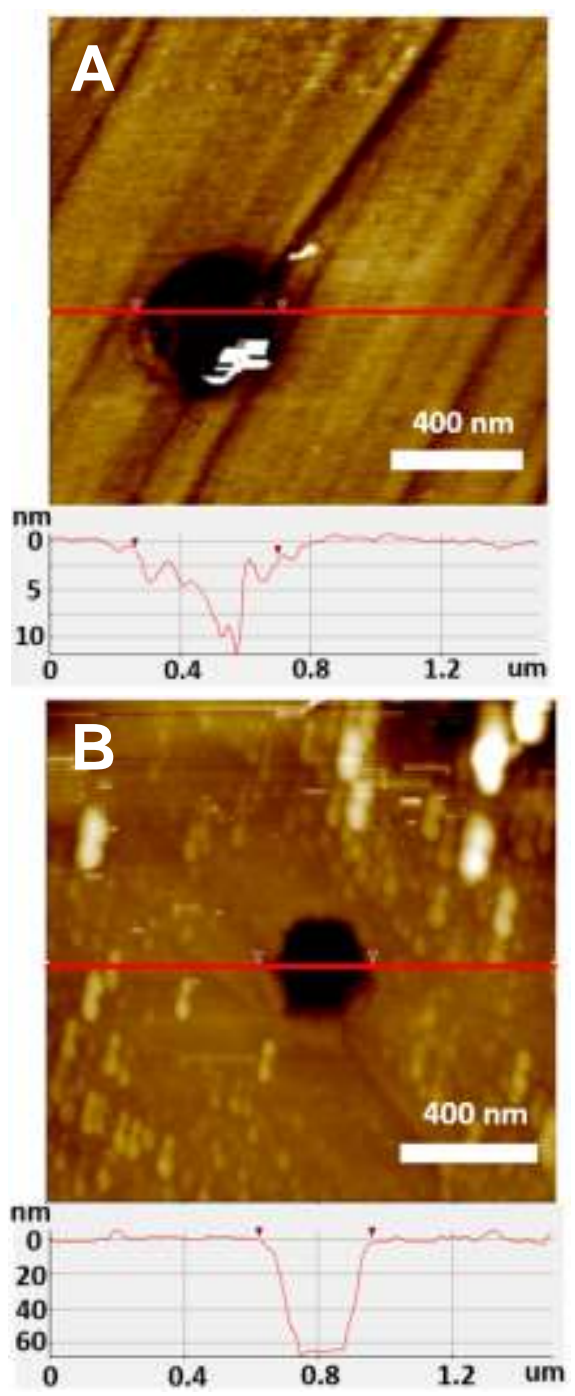

Figure 1. Noncontact-mode AFM topographic images of (A) a polished Pt nanoelectrode and (B) the same electrode after 400 potential pulses applied in the aqueous solution containing 20 $\mathrm{mM} \mathrm{N}_{2} \mathrm{H}_{4}$ and $5 \mathrm{mM} \mathrm{KNO}_{3}$. The red lines in $\mathrm{A}$ and $\mathrm{B}$ correspond to the shown cross-sections.

Figure $\mathrm{S} 1 \mathrm{~A}$ shows a cyclic voltammogram of $0.5 \mathrm{M} \mathrm{H}_{2} \mathrm{SO}_{4}$ solution at a 207-nm-radius Pt electrode. With the well-defined hydrogen, double layer and oxygen regions, this voltammogram shape is similar to that in Fig. S1B, which was obtained at a macroscopic Pt electrode.

A steady-state voltammogram of $1 \mathrm{mM}$ ferrocenemethanol $(\mathrm{FcMeOH})$ in $0.2 \mathrm{M} \mathrm{KCl}$ (Fig. S2) was obtained at the Pt electrode imaged in Fig. 1 before the ORR. Using Eq. 1 for the 
steady-state diffusion limiting current $\left(i_{\mathrm{d}}=47 \mathrm{pA}\right)$

$$
i_{d}=4 D F a c^{*}
$$

where $F$ is the Faraday constant, $D$ and $c^{*}$ are the diffusion coefficient $\left(7.8 \times 10^{-6} \mathrm{~cm}^{2} / \mathrm{s}^{17}\right)$ and the bulk concentration of $\mathrm{FcMeOH}$, respectively, $a=160 \mathrm{~nm}$ was calculated in agreement with the AFM images in Fig. 1. The $\leq 12 \mathrm{~nm}$ Pt recess in Fig. 1A is $<0.1 a$, i.e., too small to significantly affect the $i_{\mathrm{d}}$ value. ${ }^{18}$

The image in Fig. 1B suggests the presence of NPs on the glass surface surrounding the etched Pt core. The larger (ca. $100 \mathrm{~nm}$ ) spots most likely are particles of electrolyte formed when the electrode was taken out of solution for AFM imaging. ${ }^{12}$ High-resolution scanning electron microscopy (SEM) images of the same electrode (Figure 2) were obtained to check whether the smaller spots represent Pt NPs.

The secondary electron SEM image in Fig. 2A shows the Pt surface after the ORR and a small portion of the surrounding glass insulator. The metal surface is recessed into glass and exhibits nm-sized pores produced by Pt etching. An SEM image obtained with backscattered electrons (Fig. 2B) shows bright spots indicative of the presence of particles composed of a material with a high atomic number (e.g., a fifth period element). In our experiments, Pt is the only element that could produce such intensities against the silica background. A higher resolution back-scattered SEM image (Fig. 2C) reveals individual Pt NPs with the diameter ca. 5 $\mathrm{nm}$ and their aggregates deposited on the glass surface.

We employed catalytic amplification of NP collisions ${ }^{19}$ to verify that Pt NPs are produced during ORR and investigate whether these NPs are released into the solution. In a conventional nano-impact experiment, a catalytically inert collector electrode is immersed in solution containing catalytic NPs and electroactive species that can react at the NP surface but not at the 


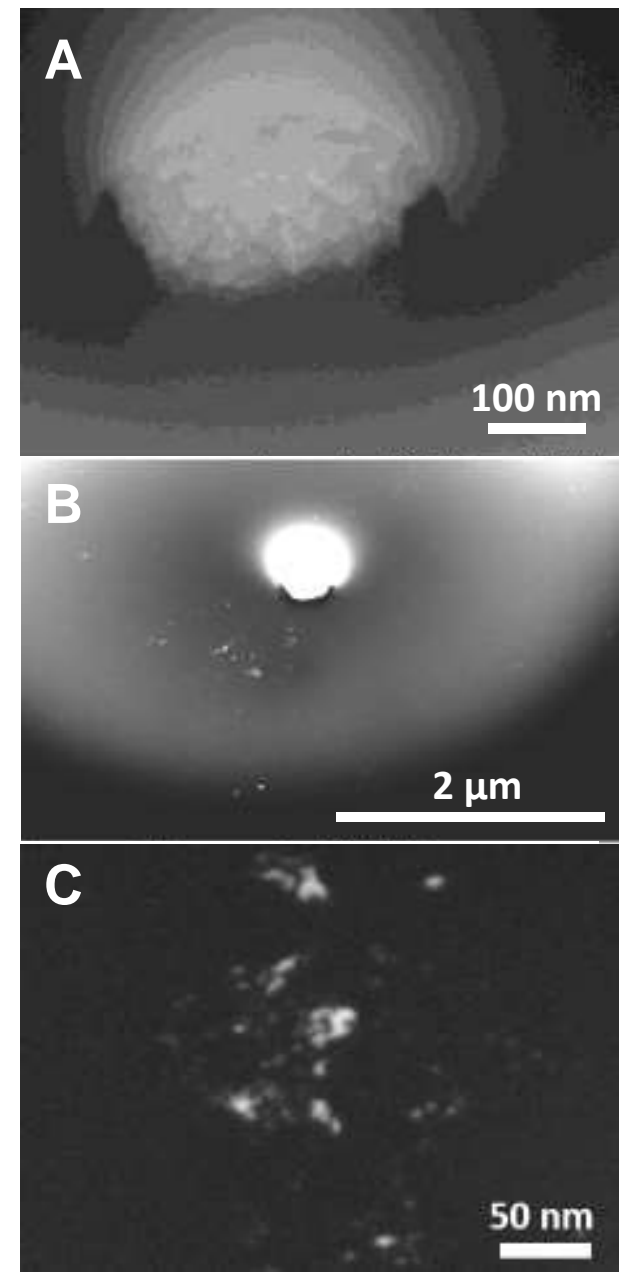

Figure 2. SEM images of a Pt electrode after the ORR. (A) SEM image obtained with secondary electrons showing the topology of the electrode surface. (B-C) SEM images obtained with backscattered electrons which is sensitive to the atomic mass contrast of the imaged materials. In this case Pt is highlighted against the background in (B) and (C) due to its high atomic number. (C) Zoom in of a portion of the glass surface from (B). The electrode is the same as in Fig. 1.

bare electrode. ${ }^{20,21}$ A NP colliding with the collector surface acts as an active nanoelectrode, and the current is produced by the diffusion of electroactive species to and electrocatalytic reaction at its surface (e.g., oxidation of hydrazine $\left.{ }^{22-26}\right)$. The resulting catalytic amplification makes the collision event detectable. In our experiments, no NPs were present in the bulk solution, and the number of particles generated by dissolving the Pt ultramicroelectrode (UME) surface was 
expected to be small. Therefore, the produced NPs had to be detected locally in a close proximity to the etched Pt surface by using the scanning electrochemical microscope (SECM). A 25- $\mu \mathrm{m}$-radius Pt disk was used as the substrate, and a 5- $\mu \mathrm{m}$-radius Hg-coated Pt disk serving as the SECM tip was positioned $\sim 10 \mu \mathrm{m}$ above the substrate surface (Fig. 3). A sequence of $1 \mathrm{~s}$ long potential pulses (see above) was applied to the substrate to produce Pt NPs whose collisions with the $\mathrm{Hg}$-coated tip were amplified by hydrazine oxidation. At the chosen tip potential $\left(E_{\mathrm{T}}=\right.$ $0.2 \mathrm{~V} v$ s. NHE), $\mathrm{N}_{2} \mathrm{H}_{4}$ oxidation at $\mathrm{Hg}$ was too slow to produce measurable current.

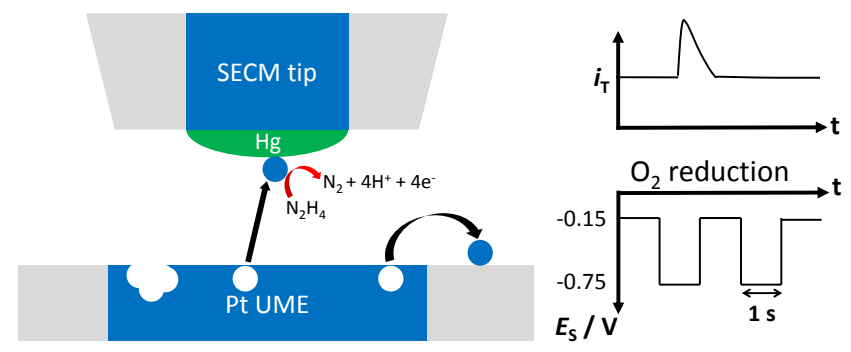

Figure 3. Schematic representation of the experimental setup for detecting NPs generated during the ORR at the Pt substrate microelectrode. The substrate potential $\left(E_{\mathrm{S}}\right)$ was pulsed between $-0.15 \mathrm{~V}$ and $-0.75 \mathrm{~V}$ to induce the $\mathrm{ORR}$ and Pt dissolution. Electrocatalytic oxidation of $\mathrm{N}_{2} \mathrm{H}_{4}$ occurred at a Pt nanoparticle during its collision with the Hg-coated UME tip, producing a current transient $\left(i_{\mathrm{T}}\right)$.

Most of Pt NPs detected in refs. 23 and 26 at a Hg UME (e.g., $50 \mathrm{~nm} \mathrm{NP}{ }^{26}$ ) were significantly larger than $\sim 5 \mathrm{~nm}$ NPs imaged in Fig. 2C. Fig. S3 in SI shows current transients produced by collisions of $5 \mathrm{~nm}$ commercial citrate-capped Pt NPs with a Hg-coated UME ( $a=5$ $\mu \mathrm{m}$ ) in aqueous solution containing $20 \mathrm{mM} \mathrm{N}_{2} \mathrm{H}_{4}$. A low concentration of supporting electrolyte $\left(5 \mathrm{mM} \mathrm{KNO}_{3}\right.$ ) was used in all collision experiments to prevent NP aggregation. ${ }^{26,27}$ The current transients in Fig. S3 are shaped like spikes rather than steps because of Pt NP deactivation at the Hg surface. ${ }^{23}$ The half-width of a typical spike ( $\sim 5 \mathrm{~ms}$; the inset in Fig. S3) is smaller than that obtained with $50 \mathrm{~nm} \mathrm{NPs},{ }^{26}$ but significantly longer than those measured for $\mathrm{H}_{2} \mathrm{O}_{2}$ oxidation at 
$\mathrm{Ru}$ and Ir oxide NPs. ${ }^{28,29}$ The collision frequency increased as concentration of the NPs was doubled (2.4 pM in Fig. S3B vs. 1.2 pM in Fig. S3A).

The SECM experiments in which potential pulses are applied to the substrate are complicated by capacitive coupling that causes spikes in the tip current. ${ }^{30,31}$ The tip current spikes are periodical and reproducible (Fig. S4). The sharp rise in $i_{\mathrm{T}}$ begins synchronously (within $1 \mathrm{~ms}$ ) with the corresponding $E_{\mathrm{S}}$ pulse and the current quickly decays to the baseline. In some experiments, this transient was followed by a much smaller $i_{\mathrm{T}}$ blip in the opposite direction (Fig. S4B). The total spike time of $\sim 10 \mathrm{~ms}$ corresponds to $1 \%$ of the substrate pulse time $(1 \mathrm{~s})$. During the remaining 99\% recording time, NP collisions with the tip electrode can be monitored without any interference from capacitive coupling. The maximum capacitive current $(\sim 100 \mathrm{pA}$ in Fig. S4) was $\sim 20-100$ times higher than the spike height in collision transients $(\sim 1-5 \mathrm{pA}$; Fig. S3). Due to their much higher amplitude and synchronization with substrate pulses, the capacitive current spikes are easy to differentiate from those produced by NP collisions.

Figure 4 shows a portion of the current recording used for in situ detection of generated $\mathrm{Pt}$ NPs with a Hg tip located $\sim 10 \mu \mathrm{m}$ above the Pt substrate UME and held at $E_{\mathrm{T}}=0.2 \mathrm{~V} v s$. NHE. In addition to high-amplitude periodic bipolar blips due to capacitive coupling, there are two

A

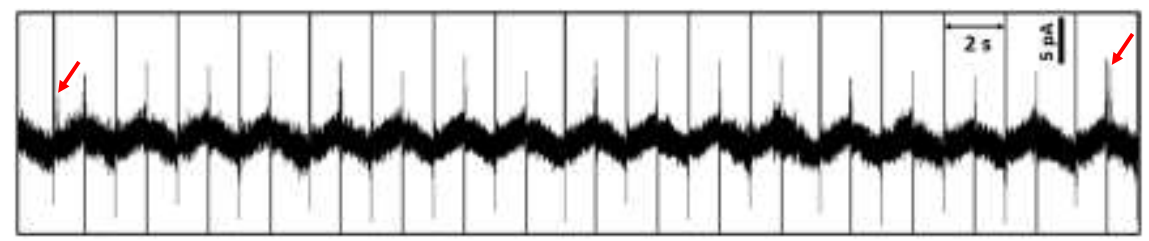

B

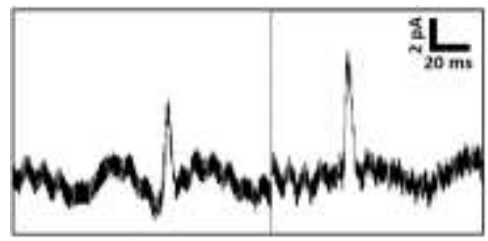

Figure 4. Detecting Pt NPs with the SECM. (A) A portion of the current trace recorded at the 5 - $\mu \mathrm{m}$-radius Hg-coated tip simultaneously with the application of 400 potential pulses to the 25- $\mu$ m-radius Pt substrate. $E_{\mathrm{T}}=0.2 \mathrm{~V}$ vs. NHE. The tip/substrate separation distance was 10 $\mu \mathrm{m}$. Solution contained $20 \mathrm{mM} \mathrm{N}_{2} \mathrm{H}_{4}$ and $5 \mathrm{mM} \mathrm{KNO}_{3}$. For other parameters, see Fig. 3. (B) Zoom in of two current spikes indicated by red arrows in A. 
spikes of anodic current indicated with red arrows. Figure 4B shows zoom-in of these spikes that can be attributed to catalytically amplified collisions of Pt NPs with the Hg tip. The shape of both spikes, their amplitudes ( $\sim 3-5 \mathrm{pA})$ and half-widths $(\sim 5 \mathrm{~ms})$ are similar to those observed with citrate-capped $5 \mathrm{~nm}$ Pt NPs in Fig. S3.

Similar spikes were obtained in several SECM experiments performed with different Pt substrates and Hg-coated tips (see, for example, Fig. S5). The spike frequency in these recordings (1 -4 spikes in 800 s long recordings) was much lower than that in Fig. S3. Unlike the experiments in Fig. S3, in which a large number of Pt NPs were present in the bulk solution, the current recordings in Figs. 4 and S5 represent the detection of just a few NPs produced in situ by the dissolution of Pt UME substrate.

We carried out control experiments to further verify that the spikes in Fig. 4 are due to the catalytically amplified NP collisions. The current trace in Fig. S6 was recorded under the same experimental conditions as the one in Fig. 4 except for $E_{\mathrm{T}}=0 \mathrm{~V} v s$. NHE at which the $\mathrm{N}_{2} \mathrm{H}_{4}$ oxidation at Pt NPs is immeasurably slow. The $800 \mathrm{~s}$ long recording showed 800 capacitive current transients, but no single spike attributable to a NP collision. In Fig. S7, all experimental conditions (including $E_{\mathrm{T}}=0.2 \mathrm{~V}$ ) were the same as in Fig. 4 except that the Hg-coated tip was located far (a few hundred $\mu \mathrm{m}$ in the $\mathrm{X}, \mathrm{Y}$, and $\mathrm{Z}$ directions) away from the Pt substrate. Again, no spikes attributable to NP collisions could be seen in this $800 \mathrm{~s}$ long current recording.

One should notice that the formation of Pt NPs cannot be attributed to hydrogen evolution reaction (HER). In neutral solutions used in this study, the HER current at a Pt nanoelectrode at $-0.75 \mathrm{~V}$ vs. NHE was very low. Moreover, HER is known to be suppressed by ORR even at higher overpotentials. ${ }^{32}$ Additionally, our previous experiments in acidic and deaerated solutions showed no appreciable dissolution of Pt. ${ }^{12}$ 
The detected NPs are not the sole product of Pt dissolution during the ORR. Percival et $a l .{ }^{14}$ recently reported the production of ionic platinum species dissolved in solution under similar experimental conditions. Highly oxidizing hydroxyl radical $\left(\mathrm{OH}^{*}\right)$ was put forward as a likely cause of cathodic dissolution of Pt during ORR. ${ }^{14}$ The production of Pt NPs during the ORR observed in our experiments can help address an important question - how $\mathrm{OH}^{\circ}$ species can induce Pt oxidation at negative potentials at which the platinum is supposed to be cathodically protected. ${ }^{14}$ A plausible explanation is that the $\mathrm{OH}^{*}$ reacts with Pt NPs near the electrode surface to produce Pt ions. This conjecture is also in agreement with the report by Noël et al. ${ }^{13}$ who suggested that $\mathrm{HO}^{*}$ is produced during $\mathrm{ORR}$ in solution rather than generated heterogeneously at the electrode, where it would have been rapidly reduced. It is possible that $\mathrm{HO}^{\bullet}$ forms at the active Pt NPs.

In conclusion, our experiments revealed that the cathodic dissolution of Pt during ORR produces Pt NPs. These $\sim 5 \mathrm{~nm}$ NPs were observed on the surface of glass surrounding the etched Pt nano-disk using high-resolution SEM with backscattered electrons. The release of Pt NPs into the solution was evidenced by monitoring their catalytically amplified collisions with an UME positioned a few $\mu \mathrm{m}$ away from the dissolving Pt surface. The production of Pt NPs during the ORR considered in the context of simultaneous formation of hydroxyl radicals ${ }^{13}$ and ionic Pt species ${ }^{14}$ provides additional insights into the mechanism of Pt dissolution at moderately negative potentials.

Another important result of this study is the first detection of a few locally generated catalytic nanoparticles by combining the electrochemical nano-impact method with SECM. Unlike previous experiments in which NP collisions with UMEs were monitored in the bulk solution containing a large number of particles, the use of the UME collector as an SECM tip 
enabled localized detection of a small number of in situ generated Pt NPs. Potential applications of this approach range from studies of dissolution processes to the detection of nanobubbles and biological vesicles produced by surface-bound living cells.

\section{ASSOCIATED CONTENT}

Supporting Information. Experimental methods, voltammograms at the Pt electrodes, current recordings showing tip/substrate coupling and control experiments. This material is available free of charge via the Internet at http://pubs.acs.org.

\section{AUTHOR INFORMATION}

\section{Corresponding Author}

*E-mail: mmirkin@qc.cuny.edu

\section{Author Contributions}

All authors have given approval to the final version of the manuscript.

$\ddagger$ These authors contributed equally.

Notes

The authors declare no competing financial interest.

\section{ACKNOWLEDGMENTS}

We gratefully acknowledge the financial support from National Science Foundation (CHE1416116) and the Brazilian funding agencies FAPESP - São Paulo Research Foundation (Process no. 2016/03347-0; RFB). This research used resources of the Center for Functional Nanomaterials, which is a U.S. DOE Office of Science Facility, at Brookhaven National Laboratory under Contract No. DE-SC0012704. 


\section{REFERENCES}

(1) Zhdanov, V. P.; Kasemo, B. Chem. Phys. Lett. 2011, 509, 134-140.

(2) Onochi, Y.; Nakamura, M.; Hoshi, N. A. J. Phys. Chem. C 2012, 116, 15134-15140.

(3) Yadav, A. P.; Okayasu, T.; Sugawara, Y.; Nishikata, A.; Tsuru, T. J. Electrochem. Soc. 2012, 159, C190-C194.

(4) Inzelt, G.; Berkes, B.; Kriston, Á. Electrochim. Acta 2010, 55, 4742-4749.

(5) Mitsushima, S.; Koizumi, Y.; Uzuka, S.; Ota, K.-I. Electrochim. Acta 2008, 54, 455-460.

(6) Matsumoto, M.; Miyazaki, T.; Imai, H. J. Phys. Chem. C 2011, 115, 11163-11169.

(7) Kongkanand, A.; Ziegelbauer, J. M. J. Phys. Chem. C 2012, 116, 3684-3693.

(8) Umeda, M.; Maruta, T.; Inoue, M.; Nakazawa, A. J. Phys. Chem. C 2008, 112, 1809818103.

(9) Yanson; A. I. Rodriguez, P.; Garcia-Araez, N.; Mom, R. V.; Tichelaar, F. D.; Koper, M. T. M. Angew. Chem. Int. Ed. 2011, 50, 6346-6350.

(10) Hersbach, T. J. P.; Yanson, A. I.; Koper, M. T. M. Nat. Commun. 2016, 7, 12653.

(11) Simonet, J.; Labaume, E.; Rault-Berthelot, J. Electrochem. Commun. 1999, 1, 252-256.

(12) Noël, J.-M.; Yu, Y.; Mirkin, M. V. Langmuir 2013, 29, 1346-1350.

(13) Noël, J.-M.; Latus, A.; Lagrost, C.; Volanschi, E.; Hapiot, P. J. Am. Chem. Soc. 2012, 134, 2835-2841.

(14) Percival, S. J.; Dick, J. E.; Bard, A. J. Anal. Chem. 2017, 89, 3087-3092.

(15) Xiao, X. Y.; Fan, F. R. F.; Zhou, J. P.; Bard, A. J. J. Am. Chem. Soc. 2008, 130, 1666916677.

(16) Nioradze, N.; Chen, R.; Kim, J.; Shen, M.; Santhosh, P.; Amemiya, S. Anal. Chem. 2013, 85, 6198-6202. 
(17) Sun, P.; Mirkin, M. V. Anal. Chem. 2006, 78, 6526-6534.

(18) Sun, P.; Mirkin, M. V. Anal. Chem. 2007, 79, 5809-5816.

(19) Xiao, X.; Bard, A. J. J. Am. Chem. Soc. 2007, 129, 9610-9612.

(20) Bard, A. J., Boika A., Kwon S. J., Park J. H., Thorgaard S. N., in Nanoelectrochemistry (Eds.: Mirkin M. V., Amemiya S.), CRC Press, 2015; pp. 241-291.

(21) Sokolov, S. V.; Eloul, S.; Kätelhön, E.; Batchelor-McAuley, C.; Compton, R. G. Phys. Chem. Chem. Phys. 2017, 19, 28-43.

(22) Xiao, X. Y.; Fan, F. R. F.; Zhou, J. P.; Bard, A. J. J. Am. Chem. Soc. 2008, 130, 1666916677.

(23) Dasari, R.; Robinson, D. A.; Stevenson, K. J. J. Am. Chem. Soc. 2013, 135, 570-573.

(24) Guo, Z. H.; Percival, S. J.; Zhang, B. J. Am. Chem. Soc. 2014, 136, 8879-8882.

(25) Dasari, R.; Tai, K.; Robinson, D. A.; Stevenson, K. J. ACS Nano 2014, 8, 4539-4546.

(26) Robinson, D. A.; Kondajji, A. M.; Castaneda, A. D.; Dasari, R.; Crooks, R. M.; Stevenson, K. J. J. Phys. Chem. Lett. 2016, 7, 2512-2517.

(27) Kleijn, S. E. F.; Serrano-Bou, B.; Yanson, A. I.; Koper, M. T. M. Langmuir 2013, 29, 2054-2064.

(28) Kang, M.; Perry, D.; Kim, Y.-R.; Colburn, A. W.; Lazenby, R. A.; Unwin, P. R. J. Am. Chem. Soc. 2015, 137, 10902-10905.

(29) Zhou, M.; Yu, Y.; Hu, K.; Xin, H.; Mirkin M. V. Anal. Chem. 2017, 89, 2880-2885.

(30) Bard, A. J.; Fan, F.-R. F.; Kwak, J.; Lev, O. Anal. Chem. 1989, 61, 132-138.

(31) Mirkin, M. V.; Arca, M.; Bard, A. J. J. Phys. Chem. 1993, 97, 10790-10795.

(32) Benn, E. E.; Gaskey, B.; Erlebacher, J. D. J. Am. Chem. Soc. 2017, 139, 3663-3668. 
TOC only

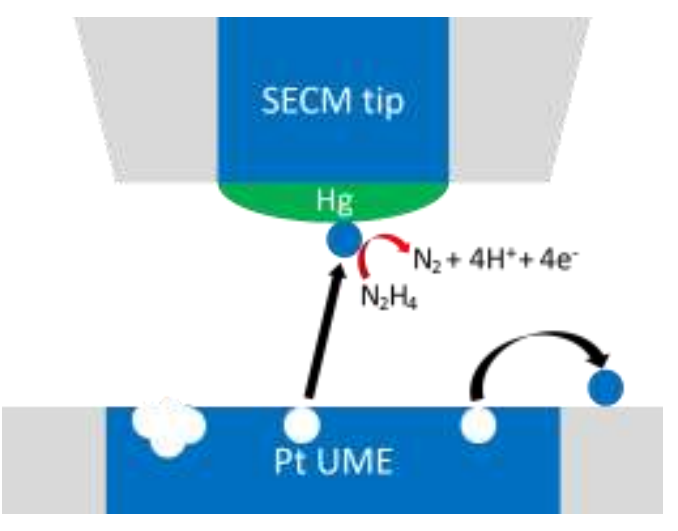

